\title{
Evaluation of the Impact of Smoking on Spondyloarthritis: Data from the Moroccan Biotherapy Register (RBSMR)
}

Bouayad $\mathrm{S}^{1^{*}}$, Rostom $\mathrm{S}^{1}$, Hmamouchi $\mathrm{I}^{2,3}$, El Binoune $\mathrm{I}^{1}$, Amine $\mathrm{B}^{1}$, Abouqal $\mathrm{R}^{2}$, Achemlal $\mathrm{L}^{4}$, Allali $\mathrm{F}^{5}$, El Bouchti $\mathrm{I}^{6}$, El Maghraoui $\mathrm{A}^{7}$, Ghozlani $\mathrm{I}^{8}$, Hassikou $\mathrm{H}^{9}$, Harzy $\mathrm{T}^{10}$, Ichchou L ${ }^{11}$, Mkinsi $\mathrm{O}^{12}$, Niamane $\mathrm{R}^{13}$, Bahiri $\mathrm{R}^{1}$

${ }^{1}$ Department of Rheumatology, A, El Ayachi Hospital, Ibn Sina University Hospital, Rabat-Sale, Morocco

${ }^{2}$ Laboratory of Epidemiology and Clinical Research, Faculty of Medicine and Pharmacy, Rabat, Morocco

${ }^{3}$ Provincial Hospital of Skhirat-Temara, Morocco

${ }^{4}$ Department of Rheumatology, Military Hospital Mohamed V, Ibn Sina University Hospital, Rabat, Morocco

${ }^{5}$ Department of Rheumatology B, El Ayachi Hospital, Ibn Sina University Hospital, Rabat-Salé, Morocco

${ }^{6}$ Department of Rheumatology, Arrazi Hospital, University Hospital Mohammed VI, Marrakech, Morocco

${ }^{7}$ Rheumatology medical office, Rabat, Morocco

${ }^{8}$ Department of Rheumatology, University Hospital Agadir, Morocco

${ }^{9}$ Department of Rheumatology, Military Hospital Meknes, Hassan II University Hospital, Morocco

${ }^{10}$ Department of Rheumatology, University Hospital Hassan II Fès, Morocco

${ }^{11}$ Department of Rheumatology, University Hospital Mohammed VI Oujda, Morocco

${ }^{12}$ Department of Rheumatology, University Hospital Ibn Rochd, Casablanca, Morocco

${ }^{13}$ Department of Rheumatology, Military Hospital Avicenne, University Hospital Mohammed VI, Marrakech, Morocco

DOI: $10.36348 /$ sjpm.2021.v06i03.004

| Received: 14.02.2021 | Accepted: 25.02.2021 | Published: 21.03.2021

*Corresponding author: Sara Bouayad

\section{Abstract}

Objective: The aim of our study was to determine the prevalence of smoking and its impact on the various parameters of spondyloarthritis based on collected data from the Moroccan biotherapy register. Materials and methods: This is a multicenter study based on data from the Moroccan biotherapy register related to patients suffering from spondyloarthritis. An analysis of the socio-demographic parameters as well as an evaluation of the variables associated with the disease were performed. Univariate and multivariate logistic regressions were conducted to assess what the impact of smoking is on the various spondyloarthritis parameters. $\mathrm{p}<0.05$ was set to be the significant threshold. Results: The study is based on data collected from 194 patients (21 smokers and 173 non-smokers) suffering from AS included in the Moroccan biotherapy register. The prevalence of smoking was $10.8 \%$. Male gender was associated with smoking (63\% of men in non-smoking group versus $90 \%$ of men in the smoking group) $(\mathrm{p}=0.006)$. In addition, a higher CRP: 8 [2-17] was observed in the smoking group compared to 5.5 [2-28] in the non-smoking group $(\mathrm{p}=0.048)$. No significant difference between the 2 groups was statistically noted in terms of the disease activity evaluated by the BASDAI and ASDAS CRP score which were respectively $2.77+/-1.82$ and $2.25 \pm 1.66$ in the smoking group and $3.24+/-2.15$ and $2.09 \pm 1.7$ in the non-smoking one. Furthermore, our results did not reveal a significant correlation between smoking and the functional impact of spondyloarthritis. No correlation was established between smoking and the structural progression of the disease. Conclusion: Our study suggests that male gender and a higher CRP are statistically associated with tobacco consumption. Larger scale studies are needed to support these results.

Keywords: Tobacco, spondyloarthritis, prevalence.

Copyright ( $\odot 2021$ The Author(s): This is an open-access article distributed under the terms of the Creative Commons Attribution 4.0 International License (CC BY-NC 4.0) which permits unrestricted use, distribution, and reproduction in any medium for non-commercial use provided the original author and source are credited.

\section{INTRODUCTION}

Spondyloarthritis is a chronic inflammatory disease which affects the sacroiliac joints, the spine and all peripheral joints causing chronic pain and progressive stiffness [1]. The global prevalence is around $1.5 \%$ and can be the cause of a major functional handicap. While genetic predisposition plays a major role in the risk of developing spondyloarthritis, other elements such as environmental factors are necessary to trigger or even maintain the disease [3].

Smoking is known to be an important environmental risk factor for the development of rheumatoid arthritis $[2,11]$. For the past ten years, some concordant studies have shown its harmful effect on the 
activity of spondyloarthritis [4, 5], on its functional repercussions [5, 6, 8] and its influence on the radiographic progression of the disease [3, 4, 7]. However, these studies are limited. Smoking interferes with the disease, the underlying mechanism being unknown. It can be noted that smoking deeply modifies the respiratory microbiota and host-bacteria interactions in the airways [10]. During spondyloarthritis, smoking has a direct pro-inflammatory effect [9], worsens the already existing inflammation and may play a role in the emergence and the evolution of the disease.

Tobacco is a factor that can be adjusted. It is therefore a target we can act on to control the disease. Thus, we have an important role to play in helping patients suffering from spondyloarthritis quit smoking. The objectives of our study are to assess the prevalence of smoking in patients with spondyloarthritis included in the Moroccan register of biotherapy (RBSMR) and to assess its impact on the various clinical, biological and structural parameters of the disease (activity, functional repercussions, and severity of the disease).

\section{PATIENTS AND METHODS}

This is a multicenter cross-sectional study (10 university hospital / rheumatology departments) using inclusion data from the Moroccan register of biotherapy (RBSMR) collected between May 2017 and December 2018. One hundred ninety four patients with spondyloarthritis were included 21 of them actively smoking. The different socio-demographic parameters of the smoking / non-smoking groups were analyzed (age, gender, smoking status) as well as the variables related to the disease (BASDAI, ASDAS, BASFI, ESR, CRP, HLA B27, syndesmophytes, coxitis, radiographic sacroiliitis or MRI).The comparison tests between the two groups were performed using Student's T test for quantitative variables with normal distribution, Mann Witheney « $U$ » test for non parametric variables with asymetric distribution and Chi2 for qualitative variables. A univariate and multivariate logistic regression were conducted to investigate the impact of smoking on the various parameters of spondyloarthritis. SPSS v20 software was the main tool for the statistical analysis and a p $<0.05$ was considered statistically significant.

\section{RESULTS}

194 patients with AS were included in this study: 21 were actively smoking and 173 were nonsmokers the prevalence of smoking being $10.8 \%$.

The mean age of patients was similar in the 2 groups $(40.3+/-13.6$ years in the smoking group and $40.2+/-13.7$ in the non-smoking one).

Male gender was associated with smoking: $63 \%$ of men in the non-smoking group versus $90 \%$ in the smoking group $(\mathrm{p}=0.006)$. HLA b27 status was positive for 6 smokers $(86 \%)$ and 29 non-smokers (63\%). No significant difference between the 2 groups was statistically noted in terms of the disease activity as evaluated by the BASDAI score (Bath Ankylosing Spondylitis Disease Activity Index) and the ASDAS CRP score which were respectively $2.77+/-1.82$ and $2.25 \pm 1.66$ in the smoking group and $3.24+/-2.15$ and $2.09 \pm 1.7$ in the other one. A correlation between smoking and a biological inflammatory syndrome was found: a higher CRP of 8 [2-17] was reported in the smoking group compared to $5.5[2-28]$ in the nonsmoking group $(\mathrm{p}=0.048)$.

In addition, our results did not reveal a significant correlation between smoking and the functional impact of spondyloarthritis as evaluated by the BASFI (Bath Ankylosing Spondylitis Functional Index): $3.34 \pm 2.91$ for the smoking group versus $3.35 \pm$ 2.38 for the non smoking group (Table-1). Smoking is not associated with the structural progression of the disease identified by radiographic sacroiliitis (20 (95\%) smokers, $150(87 \%)$ non-smokers), the presence of syndesmophytes (10 (47.6\%) smokers, 61 ( 35.3\%) non-smokers) and the presence of ultrasound coxitis (4 (31\%) smokers, 17 (18\%) non-smokers) (Table-2).

Table-1: Characteristics of included patients

\begin{tabular}{|l|l|l|l|}
\hline & & & \\
\hline Age $^{1}($ years $)$ & $40.3 \pm 13.6$ & $40.2 \pm 13.7$ & 0.995 \\
\hline Male sex $^{2}$ & $19(90)$ & $109(63)$ & 0.006 \\
\hline BASDAI $^{1}$ & $2.77 \pm 1.82$ & $3.24 \pm 2.15$ & 0.378 \\
\hline BASFI $^{1}$ & $3.34 \pm 2.91$ & $3.35 \pm 2.38$ & 0.985 \\
\hline ASDAS CRP $^{1}$ & $2.25 \pm 1.66$ & $2.09 \pm 1.7$ & 0.707 \\
\hline ESR $^{3}(\mathrm{~mm} / \mathrm{h})$ & $14[6.5-48]$ & $20[8-35]$ & 0.450 \\
\hline $\mathrm{CRP}^{3}(\mathrm{mg} / \mathrm{L})$ & $6[2-17]$ & $5.5[2-28]$ & 0.048 \\
\hline $\mathrm{HLA} \mathrm{B}^{2} 7^{2}$ & $6(86)$ & $29(63)$ & 0.400 \\
\hline
\end{tabular}

1: Mean and standard deviation, 2: Number and percentage, 3: Median and interquartiles 
Table-2: Smoking and radiographic progression

\begin{tabular}{|l|l|l|l|}
\hline & & & \\
\hline Radiographic Sacroiliitis $^{2}$ & $20(95)$ & $150(87)$ & 0.47 \\
\hline Syndesmophytis & $10(47.6)$ & $61(35.3)$ & 0.34 \\
\hline Ultrasound Coxitis $^{2}$ & $4(31)$ & $17(18)$ & 0.28 \\
\hline
\end{tabular}

1: Mean and standard deviation, 2: Number and percentage, 3: Median and interquartiles

\section{DISCUSSION}

Our study suggests that tobacco consumption is associated with the male gender and a more elevated CRP. The prevalence of smoking in patients with spondyolarthritis from our series was $10.8 \%$. It varies between $37.2 \%$ and $76 \%$ depending on the different studies reported in the literature [11-13]. This could be explained by the difference in socio-demographic parameters of the studied populations and their life habits. Male gender is significantly associated with tobacco consumption in our study corroborating with the results reported in the literature. The highest percentage was reported by Zhang and al. (348 male patients out of 425 patients included in the study, ie $81.9 \%$ ) [13]. This difference can be explained by the fact that Moroccan women consider smoking as a taboo topic and do not always say the truth about their smoking habits. In our study, we found a strong correlation between biological inflammatory syndrome, essentially CRP and tobacco. This link is explained by the fact that smoking acts on the inflammation parameters through various mechanisms [14, 15] and promotes low-grade systemic inflammation [16]. Several studies have identified smoking as a factor that worsens inflammation in axial spondyloarthritis [17, 20-22] and this inflammation depends on the cumulative dose of tobacco [24]. Chen and al's study of 75 AS patients (35 smokers among them) mentioned that the biological inflammatory syndrome was more significant for the smoking group with AS compared to the non smoking one $[17,23]$.

In addition, a few studies have reported a significant correlation between smoking and AS activity (BASDAI, ASDAS CRP) [26] as well as between smoking and functional impairment (BASFI). This association was not retrieved in our test population and this may be due, among other factors, to the small size of our sample compared to the ones studied in the literature, to the subjective nature of the BASDAI and BASFI questionnaires as well as the high illiteracy rate of our patients. In the French multicenter prospective cohort of recent undifferentiated spondyloarthropathy DESIR (it included patients with recent inflammatory rachialgia of less than 3 years suggestive of spondyloarthritis) [19], 37.2\% of the 647 patients were smokers (old or active). Smoking was associated in multivariate analysis with a higher disease activity, assessed by BASDAI and ASAS-CRP (regardless of B27 status). In the Swiss cohort SCQM (Swiss Clinical Quality Management in Rheumatic Diseases) including 1129 patients receiving treatment for axial SA, the smoking rate was $37 \%$. The activity of the disease, evaluated by BASDAI, was again significantly higher in the smoking group but only in the HLA B27 positive subgroup. This was not the case in the HLA B27 negative subgroup [27]. This interaction between tobacco and HLA B27 was not found in the DESIR cohort given the much higher proportion of HLA B27 positive subjects in the Swiss cohort (84\% compared to $65 \%$ in DESIR). A higher BASDAI and ASDAS were also found in the smoking group of patients with spondyloarthritis in the baseline of the Swiss SCQM cohort [18].

In our series, we did not find a significant correlation between smoking and the radiographic progression of the disease (coxitis, syndesmophytes, sacroiliitis). The causal relationship between smoking and the progression of $\mathrm{SpA}$ is still not well established in the literature [25]. The GErman SPondyloarthritis Inception Cohort (GESPIC cohort) included 210 patients with axial spondyloarthritis and tried to assess the factors associated with radiographic progression (defined by an increase of the mSASSS score greater than 2 points over 2 years) [29]. In multivariate analysis, smoking appeared to be an independent factor associated with radiological progression $(\mathrm{OR}=2.10$; 95\% CI: 1.03-4.30). In addition, the importance of the radiographic progression was proportional to the smoking frequency: the progression of the mSASSS score was on average $2.20 \pm 4.62$ in heavy smokers (> 10 cigarettes per day) against $0.48 \pm 1,48$ in light smokers ( $\leq 10$ cigarettes per day) $[25,28]$. The DESIR cohort also showed that smoking was correlated with more frequent inflammatory lesions of the sacroiliac and spine on MRI.

Our work has some limitations, namely the small size of the sample and given the nature of the register, some data is missing such as the duration and the cumulative dose of smoking. These parameters are necessary when looking for a dose dependency effect on the severity of the disease as well as the search for cardiovascular comorbidities in tobacco consumers suffering from SA. In addition, we have presented the descriptive results of the inclusion data from the multicenter study of the first Moroccan and African registry of biotherapies that will monitor these patients over a period of 3 years. This will allow us to assess the impact of smoking on the outcome and the evolution of the disease. 


\section{CONCLUSION}

Our study suggests that male gender and a biological inflammatory syndrome (more elevated CRP) are significantly associated with smoking, while the latter is not linked to the functional and structural activity of the disease and its impacts. Given the relatively young age of most of our spondyloarthritis patients, it is justified to act in order to prevent smoking, or at least advise and help patients limit their tobacco consumption to reduce the additional cardiovascular risk and potentially improve their longterm prognosis.

\section{DECLARATIONS}

Ethics approval and consent to participate: The protocol for the original RBSMR study was reviewed and approved by local institutional review boards and the national ethic committee: Ethics committee for biomedical research Mohammed V universityRABAT. Faculty of medicine and pharmacy of RABAT. The committee's reference number: 117/17

Consent to publish: This project has been reviewed and accepted by the scientific committee of the RBSMR study. Moreover, this committee has reviewed this current manuscript and has agreed upon its submission to your journal.

Availability of data and materials: All data generated or analyzed during this study are included in this published article.

Acknowledgements: The authors would like to thank the scientific Committee and national principal investigators of the RBSMR study: Lahcen Achemlal, Fadoua Allali, Rachid Bahiri, Imane El Bouchti, Imad El Ghozlani, Abellah El Maghraoui, Toufik Harzy, Ihsane Hmamouchi, Linda Ichchou, Ouafa Mkinsi, and Redouane Niamane; patients who agreed to participate in this study.

Funding information: Data collection for the Moroccan Register of biotherapy "Registre de Biothérapies de la Société Marocaine de Rhumatologie" (RBSMR) was supported by an unrestricted grant from Pfizer, Novartis, Janssen, and Abbvie. The ancillary study described in this manuscript was conducted without any type of funding.

Competing interests: No competing interests.

Authors' Contributions: We declare that we participated to the study as following:

SB performed the statistical analysis and interpretation and prepared the manuscript. SR participated in the article writing and critical review of the manuscript. IH reviewed and interpreted the statistical analysis. RB participated in the critical review of the manuscript. All authors read and approved the final manuscript.

\section{REFERENCES}

1. Zochling, J., Brandt, J., \& Braun, J. (2005). The current concept of spondyloarthritis with special emphasis on undifferentiated spondyloarthritis. Rheumatology, 44(12), 14831491.

2. McInnes, I. B., \& Schett, G. (2011). The pathogenesis of rheumatoid arthritis. New England Journal of Medicine, 365(23), 2205-2219.

3. Schaeverbeke, T., Truchetet, M. E., \& Richez, C. (2015). Rôle des facteurs d'environnement dans les spondyloarthrites. Revue $d u \quad$ Rhumatisme Monographies, 82(1), 3-6.

4. Averns, H. L., Oxtoby, J., Taylor, H. G., Jones, P. W., Dziedzic, K., \& Dawes, P. T. (1996). Smoking and outcome in ankylosing spondylitis. Scandinavian journal of rheumatology, 25(3), 138-142.

5. Kaan, U., \& Ferda, Ö. (2005). Evaluation of clinical activity and functional impairment in smokers with ankylosing spondylitis. Rheumatology international, 25(5), 357-360.

6. Doran, M. F., Brophy, S., MacKay, K., Taylor, G., \& Calin, A. (2003). Predictors of longterm outcome in ankylosing spondylitis. The Journal of rheumatology, 30(2), 316-320.

7. Ward, M. M., Hendrey, M. R., Malley, J. D., Learch, T. J., Davis Jr, J. C., Reveille, J. D., \& Weisman, M. H. (2009). Clinical and immunogenetic prognostic factors for radiographic severity in ankylosing spondylitis. Arthritis Care \& Research, 61(7), 859-866.

8. Kaan, U., \& Ferda, Ö. (2005). Evaluation of clinical activity and functional impairment in smokers with ankylosing spondylitis. Rheumatology international, 25(5), 357-360.

9. Chung, H. Y., Machado, P., van der Heijde, D., d'Agostino, M. A., \& Dougados, M. (2011). HLAB27 positive patients differ from HLA-B27 negative patients in clinical presentation and imaging: results from the DESIR cohort of patients with recent onset axial spondyloarthritis. Annals of the rheumatic diseases, 70(11), 1930-1936.

10. Klareskog, L., Padyukov, L., \& Alfredsson, L. (2007). Smoking as a trigger for inflammatory rheumatic diseases. Current opinion in rheumatology, 19(1), 49-54.

11. Kona, I., Essouiri, J., Awassi, F., Nessrine, A., Zahra, A. F., \& Harzy, T. (2016). Spondyloarthrite axiale et tabac. Revue du Rhumatisme, 1(83), A258.

12. Chung, H. Y., Machado, P., Van Der Heijde, D., d'Agostino, M. A., \& Dougados, M. (2012). Smokers in early axial spondyloarthritis have earlier disease onset, more disease activity, inflammation and damage, and poorer function 
and health-related quality of life: results from the DESIR cohort. Annals of the rheumatic diseases, 71(6), 809-816.

13. Zhang, S., Li, Y., Xu, X., Feng, X., Yang, D., \& Lin, G. (2015). Effect of cigarette smoking and alcohol consumption on disease activity and physical functioning in ankylosing spondylitis: a cross-sectional study. International journal of clinical and experimental medicine, 8(8), 13919.

14. Bazzano, L. A., He, J., Muntner, P., Vupputuri, S., \& Whelton, P. K. (2003). Relationship between cigarette smoking and novel risk factors for cardiovascular disease in the United States. Annals of internal medicine, 138(11), 891-897.

15. Fröhlich, M., Sund, M., Löwel, H., Imhof, A., Hoffmeister, A., \& Koenig, W. (2003). Independent association of various smoking characteristics with markers of systemic inflammation in men: results from a representative sample of the general population (MONICA Augsburg Survey 1994/95). European heart journal, 24(14), 1365-1372.

16. Wannamethee, S. G., Lowe, G. D., Shaper, A. G., Rumley, A., Lennon, L., \& Whincup, P. H. (2005). Associations between cigarette smoking, pipe/cigar smoking, and smoking cessation, and haemostatic and inflammatory markers for cardiovascular disease. European heart journal, 26(17), 1765-1773.

17. Chen, C. H., Chen, H. A., Lu, C. L., Liao, H. T., Liu, C. H., Tsai, C. Y., \& Chou, C. T. (2013). Association of cigarette smoking with Chinese ankylosing spondylitis patients in Taiwan: a poor disease outcome in systemic inflammation, functional ability, and physical mobility. Clinical rheumatology, 32(5), 659-663.

18. Ciurea, A., Scherer, A., Weber, U., Nissen, M., Exer, P., Bernhard, J., ... \& Finckh, A. (2013). OP0096 Tobacco smoking is associated with increased disease activity in HLA-B27 positive axial spondyloarthritis patients, but does not alter the course of disease activity. Annals of the Rheumatic Diseases, 71(Suppl 3), 85-85.

19. Chung, H. Y., Machado, P., Van Der Heijde, D., d'Agostino, M. A., \& Dougados, M. (2012). Smokers in early axial spondyloarthritis have earlier disease onset, more disease activity, inflammation and damage, and poorer function and health-related quality of life: results from the DESIR cohort. Annals of the rheumatic diseases, 71(6), 809-816.

20. Chung, H. Y., Machado, P., Van Der Heijde, D., d'Agostino, M. A., \& Dougados, M. (2012). Smokers in early axial spondyloarthritis have earlier disease onset, more disease activity, inflammation and damage, and poorer function and health-related quality of life: results from the DESIR cohort. Annals of the rheumatic diseases, 71(6), 809-816.

21. Ciurea, A., \& Finckh, A. (2013). Tabac et spondylarthrite. Revue du rhumatisme, 3(80), 201 203.

22. Wendling, D., Prati, C., Guillot, X., \& GodfrinValnet, M. (2013). Tabac et spondyloarthrite. La Lettre du rhumatologue, (397), 21-23.

23. Wendling, D., Guillot, X., Gossec, L., Prati, C., Saraux, A., \& Dougados, M. (2018). La rémission est associée à la CRP et au tabagisme dans la spondyloarthrite axiale débutante. La cohorte DESIR. Revue du Rhumatisme, 85(2), 178-182.

24. Zhao, S., Challoner, B., Khattak, M., Moots, R. J., \& Goodson, N. J. (2017). Increasing smoking intensity is associated with increased disease activity in axial spondyloarthritis. Rheumatology international, 37(2), 239-244.

25. Villaverde-García, V., Cobo-Ibáñez, T., CandelasRodríguez, G., Seoane-Mato, D., del CampoFontecha, P. D., Guerra, M., ... \& Cañete, J. D. (2017, April). The effect of smoking on clinical and structural damage in patients with axial spondyloarthritis: a systematic literature review. In Seminars in arthritis and rheumatism (Vol. 46, No. 5, pp. 569-583). WB Saunders.

26. Fallahi, S. (2017, August). Relationship of smoking quantity with outcome measures in patients with ankylosing spondylitis: Comments on the article by Villaverde-García V. et al. In Seminars in arthritis and rheumatism (Vol. 47, No. 1, p. e9).

27. Ciurea, A., \& Finckh, A. (2013). Smoking and spondyloarthritis. Joint Bone Spine; 80:234-235.

28. Poddubnyy, D., Haibel, H., Listing, J., MärkerHermann, E., Zeidler, H., Braun, J., ... \& Rudwaleit, M. (2013). Cigarette smoking has a dose-dependent impact on progression of structural damage in the spine in patients with axial spondyloarthritis: results from the GErman SPondyloarthritis Inception Cohort (GESPIC). Annals of the rheumatic diseases, 72(8), 1430-1432.

29. Poddubnyy, D., Haibel, H., Listing, J., MärkerHermann, E., Zeidler, H., Braun, J., ... \& Rudwaleit, M. (2012). Baseline radiographic damage, elevated acute- phase reactant levels, and cigarette smoking status predict spinal radiographic progression in early axial spondylarthritis. Arthritis \& Rheumatism, 64(5), 1388-1398. 